\title{
A POLÍTICA NACIONAL DE RECURSOS HÍDRICOS E AS ÁGUAS SUBTERRÂNEAS
}

\author{
Aldo da Cunha Rebouças ${ }^{1}$
}

\begin{abstract}
Fresh water is not, of course, just like petroleum: it is a much more valuable resource human and most of the life cannot exist without it. The paradox is that we value such a valuable resource so little, mostly when it is a hidden resource like groundwater. However, there are no technological limitations to reaching the deeper and confined aquifers in Brazil and in their major cities several thousands of private uncontrolled wells are used to supply industries, hotels, hospitals and private joint ownerships, mainly. Moreover, for much of the country groundwater may be also important as a source for livestock, base flows to rivers, and in contributing to surface water reservoirs, wetland water balance and ecology. Since the Federal Constitution of 1988 , at least, water resource management is an important and complex area of governmental resource management and environmental policies. Unfortunately, when water resource problems occur governments often respond by assigning the problems to administrative organisations insufficiently equipped to cope with them. This situation occurs because, while the problems have multiple and interdependent causes, most of the organisations facing these challenges tend to be fragmented, working with a close decision process. Moreover, water laws, such as the Federal law 9.433/97, are often inadequate, confusing or difficult to apply and the managers have to developed specific strategies to deal with the high level of uncertainty in groundwater management: in particullar, additional information needs to be acquired to reduce uncertainty, but at the same time cost-effective action is needed to avoid the possibility of future degradation of groundwater resources. Finally, there is the problem of informing and educating the public and the decision makers: it is necessary to find appropriate ways and means of disseminating information and popularizing understanding of the nature of this hidden resource.
\end{abstract}

\section{Introdução}

No Brasil, a utilização da água subterrânea para abastecimento das populações, principalmente, teve grande desenvolvimento empírico no Período Colonial $(1500$ - 1822). Durante o Primeiro Reinado (1822-1831), na Regência Trina (1831-1840) e no Segundo Reinado (18401889) a perfuração de poços, no Brasil, só podia ser feita mediante autorização Central.

A República foi proclamada em 1889, porém, somente em 1907 foi apresentado o projeto do Código de Águas, o qual, embora marco fundamental ao desenvolvimento do setor hidrelétrico, principalmente, passou 27 anos tramitando no Congresso Nacional, sendo finalmente sancionado pelo Poder Executivo em 1934 (Decreto 24.643 de 10/7/34).

Em relação às águas subterrâneas o art. 96 do Código de Águas de 1934, assim estabelece: "O dono de qualquer terreno poderá apropriar-se por meio de poços, galerias, etc., das águas que existam debaixo da superfície de seu prédio, contanto que não prejudique aproveitamentos existentes nem derive ou desvie de seu curso natural águas públicas dominicais, públicas de uso comum ou particulares", ou seja, esta era considerada um bem privado.

Dentre as alterações feitas pela Constituição Federal de 1988 aos

1 Prof. Titular da Universidade de São Paulo; Orientador de Pós-Graduação - Instituto de Geociências; Pesquisador Instituto de Estudos Avançados; Consultor Secretaria Nacional de Recursos Hídricos - SRH/OEA; Consultor Superintendência Recursos Hídricos - Bahia- SRH/BM. 
dispositivos do Código de Águas de 1934, destaca-se o fato de todas as águas do Brasil passarem, desde então, a ser um bem natural de domínio público. Nesta abordagem, são bens dos Estados (art. 26): "as águas superficiais ou subterrâneas, fluentes, emergentes e em depósito, ressalvadas, neste caso, na forma da lei, as decorrentes de obras de União".

Não obstante, a utilização da água subterrânea, no Brasil, continua sendo feita de forma empírica, improvisada e não controlada, resultando em freqüentes problemas de interferência entre poços, redução dos fluxos de base dos rios, impactos em áreas encharcadas ou pantanais e redução das descargas de fontes ou nascentes. Além disso, os poços construídos, operados e abandonados sem controle - Federal, Estaduais ou Municipais se transformam em verdadeiros focos de poluição das águas subterrâneas que são extraídas, sobretudo, daqueles localizados no meio urbano (PACHECO; REBOUÇAS, 1982).

Entretanto, durante as últimas décadas do século $X X$ a alternativa de utilização da água subterrânea tornou-se, regra geral, a solução mais barata aos problemas de abastecimento público, industrial e até irrigação, em todas as faixas climáticas da Terra. Desta forma, a falta de um controle em prol do seu uso e proteção - Federal, Estaduais ou Municipais - torna-se cada vez mais preocupante.

\section{Arcabouço Institucional e Legal Vigentes}

A Constituição Nacional de 1988 extinguiu o conceito de bem natural privado que era dado às águas subterrâneas no art. 96 do Código de Águas de 1934. Todavia, embora o controle pelo poder público Federal, Estaduais e Municipais - em prol do seu uso e proteção fosse previsto nos seus artigos 97 a 101 do Código de Águas de 1934, nunca foi, praticamente, aplicado.

Além disso, embora avançado para a época em que surgiu, o Código de Águas de 1934 não foi complementado pelas leis e pelos regulamentos nele previstos, em particular os referentes ao uso e proteção das águas subterrâneas. Mesmo nos aspectos referentes às águas superficiais, o que se teve foi uma legislação geradora de conflitos entre os interesses crescentes do setor hidrelétrico e da irrigação, principalmente.

Por sua vez, o Código de Águas Minerais de 1945 vigente (Decreto Lei 7.841/45) estabelece que poderão ser engarrafadas as águas minerais e potáveis de mesa, assim definidas. "Art. $1^{\circ}$ - Águas minerais são aquelas provenientes de fontes naturais ou de fontes artificialmente captadas que possuam composição química ou propriedades físicas ou físico-quimicas distintas das águas comuns, com características que Ihes confiram uma ação medicamentosa. Art. $3^{\circ}-$ Serão denominadas águas potáveis de mesa, as águas de composição normal, provenientes de fontes naturais ou de fontes artificialmente captadas que preencham tão somente as condições de potabilidade para a região" (ABINAM/DNPM, 1995).

Por sua vez, o Código de Mineração (Decreto Lei 227/67) em seu art. $5^{\circ}$, Inciso IX classifica entre as jazidas minerais as águas subterrâneas e fixa que as mesmas serão regidas por lei especial (art. $10^{\circ}, \mathrm{V}$ ). Assim, a ação do Departamento Nacional da Produção Mineral - DNPM ficou restrita ao controle da extração e envasamento da água subterrânea que é classificada como mineral ou potável de mesa, bem como aquela classificada como termomineral e utilizada para fins balneoterápicos, principalmente.

A divergência da legislação de águas, no Brasil, é bem ilustrada quando a Lei 6.662/79 estabeleceu a Política Nacional de Irrigação e transferiu para o Ministério do Interior (MINTER), a responsabilidade sobre o uso dos recursos hídricos para irrigação, até então atribuição do Ministério das Minas e Energia, por meio do seu Departamento Nacional de Águas e Energia Elétrica DNAEE. Embora discipline a utilização de águas subterrâneas para fins de irrigação, sua prática só abrangeu as águas superficiais (TOMANIK, 1999 e BARTH, 1999).

Note-se que a Associação Brasileira da Industria de Águas MineraisABINAM/DNPM, 1995, sinalizam a possibilidade de se virar o século $X X$ produzindo cerca de 2 bilhões de litros anuais de água engarrafada no Brasil. Tratase, portanto, de uma produção ainda muito pequena, comparativamente ao fato dos 4229 municípios abastecidos no Brasil, 2594 ou $61 \%$ utilizarem o manancial de água 
subterrânea - 10\% por poços escavados, $70 \%$ por poços tubulares e $19 \%$ captarem fontes ou minas (IBGE, 1992). Além disso, em todas as áreas metropolitanas do Brasil vários milhares de poços privados e não controlados são utilizados para abastecimento de hotéis de luxo, hospitais, industrias, condomínios, postos de serviço e clubes esportivos, principalmente.

Em termos de população que usa a água subterrânea, estima-se que os 10 mil poços tubulares em operação na Região Metropolitana de São Paulo produzindo uma vazão média de $5 \mathrm{~m}^{3} / \mathrm{h}$ cada, produzem cerca de 1,2 milhão $\mathrm{m}^{3} /$ dia, ou seja, um volume suficiente para abastecer uma população equivalente da ordem de 8 milhões de habitantes com uma taxa média per capita de 150 L/dia (REBOUÇAS et al., 1994). Além disso, cerca de $72 \%$ dos municípios do estado de São Paulo são abastecido total ou parcialmente por poços tubulares, cuja população é da ordem de 5 milhões de habitantes (CETESB, 1998).

Assim, estima-se que cerca de $50 \%$ do contingente atual de 170 milhões de habitantes (IBGE, 2000) se abasteceria do manancial subterrâneo. Portanto, a extração de água subterrânea não controlada - nos níveis Federal, Estaduais ou Municipais atinge no Brasil cerca de 4,6 trilhões de litros por ano, ou seja, da ordem de 2000 vezes superior à produção do volume controlado pelo DNPM.

Por sua vez, note-se que a captação atual de água subterrânea, no Brasil, vem sendo feita, principalmente, por meio de poços tubulares e que alguns captam água de aqüíferos confinados situados até 2000 metros de profundidade. Desta forma, as águas subterrâneas produzidas são quentes, minerais ou potáveis de mesa e, portanto, pela legislação em vigor, seriam passíveis de serem controladas pelo DNPM. Entretanto, o que se tem é que estas águas são livremente utilizadas, sobretudo, para abastecimento de cidades, indústrias ou irrigação.

A necessidade de uma legislação especial para as águas subterrâneas já era considerada pelo Código de Mineração de 1967. Esta necessidade foi, também, sentida por todos aqueles que fazem a Associação Brasileira de Águas Subterrâneas - ABAS, desde sua fundação em 1978. Assim, a ABAS criou comissões para elaborar uma proposta de lei federal sobre o uso e proteção - quantitativa e qualitativa - das águas subterrâneas no Brasil, a qual foi discutida em várias ocasiões.

O texto resultante foi enviado à Câmara Federal, cujo Projeto de Lei recebeu o número 7.127/86. Entretanto, em função, certamente, das disputas burocrática da gestão das águas, entre o Departamento Nacional da Produção Mineral - DNPM e o Departamento Nacional de Águas e Energia Elétrica - DNAEE, a Câmara Federal aprovou o referido projeto de lei dando ao DNPM a sua coordenação, enquanto no Senado a aprovação dava ao DNAEE.

Quando já se esperava a votação final do referido Projeto de Lei na Câmara Federal foi criado, em 1995, o Ministério do Meio Ambiente, dos Recursos Hídricos e da Amazônia Legal - MMA e, neste, a Secretaria Nacional de Recursos Hídricos $\mathrm{SRH}$, cabendo-lhe: o planejamento, coordenação, supervisão e controle das ações relativas aos recursos hídricos; formulação e execução da política nacional dos recursos hídricos.

Como corolário, arquivou-se o Projeto de Lei $n^{0} 7.127 / 86$ e sob a égide do MMA/SRH foi sancionada a Lei Federal 9.433/97 que organiza o setor de planejamento e gestão dos recursos hídricos em âmbito nacional, introduzindo vários instrumentos de política (COSTA, 2001).

Este instrumento legal é, sem dúvida, atual, avançado e importante. Entretanto, por mais que fale de gestão integrada, a prática coloca em destaque as águas superficiais. A mesma ênfase foi dada nas Constituições Estaduais de 1989, nos seus Planos Federal e Estaduais de Recursos Hídricos e nas leis correlatas (MMA/SRH, 2001).

Além disso, embora a Lei Federal 9.433/97 e a Lei Federal $n^{\circ}$ 9.984/00 que criou a Agência Nacional de Águas - ANA sejam estruturadas e articuladas a partir da descentralização e de uma visão sistêmica e moderna, principalmente, ações extraordinárias são anunciadas, sem qualquer consideração aos seus princípios básicos e instrumentos essenciais. Por fim, ressalte-se que estas novas leis estabelecem um arranjo institucional claro, onde tais ações são, agora, prerrogativas das agências de bacia, sob o comando político do correspondente comitê formado pelos usuários de recursos hídricos e pelas demais partes interessadas na gestão da 
gota d'água disponível. Serão esses, os comitês de bacia, que decidirão, por exemplo, sobre a necessidade de transposição de bacias hidrográficas, quando e quanto cobrar pelo uso dos rios, das águas subterrâneas e de reuso, principalmente.

\section{O Papel da Agência Reguladora de Águas - ANA}

Para garantir uma atuação descentralizada, a lei de criação da ANA estabelece que esta deverá celebrar contratos de gestão com as agências de bacia, que serão entidades não governamentais atuando em cada bacia hidrográfica, sob o comando político do correspondente comitê de bacia, formado pelos usuários de recursos hídricos e pelas demais partes interessadas na gestão da gota de água disponível na bacia em apreço. Serão esses, os comitês de bacia, que decidirão quando e quanto cobrar pelo uso da gota de água disponível (MMA/SRH, 2001).

Entretanto, o célebre binômio oferta/demanda aparece como uma das mais importantes referências quando se trata da valoração econômica da água dos rios. Por outro lado, nada se fala da gestão da demanda, ou seja, da otimização dos usos da gota d'água disponível - rios, águas subterrâneas e de reuso, principalmente experiência de sucesso comprovado em alguns países desenvolvidos, mostrando a possibilidade de se atender demandas hídricas futuras crescentes por meio da maior eficiência dos usos atuais.

Por sua vez, estabelece 0 art. $4^{\circ}$ da Lei Federal 9.984/00: "A atuação da ANA obedecerá aos fundamentos, objetivos e instrumentos da Política Nacional de Recursos Hídricos e será desenvolvida em articulação com órgãos e entidades públicas e privadas integrantes do Sistema Nacional de Gerenciamento de Recursos Hídricos". Desta forma, embora a água subterrânea seja do domínio das Unidades da Federação, o seu uso e proteção são regulados pelo Conselho Nacional de Recursos Hídricos, cuja Resolução n 15/01 criou a Comissão Permanente de Água Subterrânea.

Portanto, a disposição da Carta Magna de 1988 que estabelece ser a água subterrânea bem público de cada uma das
Unidades da Federação, sugere a necessidade dos Estados se articularem entre si, nos casos de formações aqüíferas que se estendem a mais de uma unidade federada, e com a União, no caso das unidades aqüíferas se estenderem a países vizinhos.

Além disso, os maiores objetivos do gerenciamento dos recursos hídricos no século XXI são à busca da oferta da gota d'água disponível pelo menor custo e a otimização do seu uso, ou seja, produzir cada vez mais com cada vez menos água. Aos ganhos econômicos assim gerados juntam-se dois outros: O primeiro, de natureza operacional, à medida que a empresa acaba dispondo de uma fonte alternativa de abastecimento, de extrema importância em regiões onde o fornecimento de água dos rios não é seguro ou onde a fonte própria de abastecimento da empresa está operando próximo ao limite. O segundo está ligado à imagem do empreendimento, já que o uso da água subterrânea, bem como o seu reuso, acaba revelando a preocupação com a otimização do uso e diminuição dos custos de produção de forma ambientalmente correta.

\section{Os Conceitos Usuário e Poluidor - Pagador}

O exemplo clássico é o ar que se respira. Sua abundância não lhe confere nenhum valor econômico, sendo difícil avaliar o quanto valeria, caso fosse escasso. Da mesma forma, pelo fato do Brasil ainda ostentar abundância de água na sua extensa e densa rede de rios que nunca secam, o reconhecimento da água como um bem finito e vulnerável ainda é, por vezes, uma questão polêmica. Entretanto, o reconhecimento do valor econômico da água deverá induzir o uso mais racional desse recurso natural, dado que serve de base à instituição da cobrança pela utilização da água dos rios, dos aqüíferos ou de reuso, principalmente.

Todavia, a idéia de abundância de água no Brasil leva à tolerância, certamente, da "estratégia da escassez" que manipula a baixa eficiência do seu fornecimento, cujas taxas de perdas totais da água captada, tratada e injetada nas redes de distribuição situam-se entre $30 \%$ e mais de $60 \%$, contra $5 \%$ a $15 \%$ nos países desenvolvidos. Além disso, se tem grandes desperdícios da água 
usada pelos usuários domésticos, principalmente, pela utilização de equipamentos sanitários obsoletos, hábitos de banhos longos ou de varrer a calçada com o jato da mangueira, dentre outros fatores. Por sua vez, os rios no Brasil continuam sendo, muitas vezes, utilizados como depositário final dos resíduos gerados pelas atividades humanas, tais como esgotos domésticos, lixos urbanos e efluentes industriais.

Note-se que $64 \%$ das empresas estatais de saneamento básico, no Brasil, não coletam se quer os esgotos domésticos nas cidades que abastecem, perto de $70 \%$ dos efluentes industriais ainda são lançados sem tratamento nos cursos de água e não se coleta a maior parte do lixo que se produz (IBGE,1992). Além disso, a poluição que é gerada nas grandes cidades é, sobretudo, grave nas suas áreas periféricas e atinge o meio rural vizinho, sobretudo, a população que mora rio abaixo, a qual perde, regra geral, o direito de se quer se banhar no rio que atravessa a região ou sua pequena cidade. (IBGE, 1992).

$\mathrm{Na}$ irrigação, chama a atenção o fato de que, embora esta seja a atividade que consome entre $60 \%$ e $70 \%$ do volume total ofertado de água doce, sobre cerca de 95\% dos quase 3 milhões de hectares irrigados, no Brasil, ainda predominam os métodos menos eficientes de uso da água ou indutores de maior consumo de energia elétrica, tais como espalhamento superficial, aspersão convencional e o pivô central (TELLES, 1999).

\section{Necessário Evoluir do Discurso à Prática}

O texto da Lei Federal 9.433/97 proclama com clareza os cinco princípios básicos praticados hoje em todos os países que avançaram na gestão das águas ou dos seus recursos hídricos, tais como:

1) Adoção da bacia hidrográfica como unidade de planejamento.

2) Usos múltiplos da água, quebrando a indesejável hegemonia do setor hidrelétrico sobre os demais.

3) O reconhecimento da água com um bem finito e vulnerável.

4) Reconhecimento do valor econômico da água.
5) Gestão descentralizada e participativa.

Ainda são aspectos relevantes da Lei Federal 9.433/97, cinco instrumentos essenciais:

1) O Plano Nacional de Recursos Hídricos.

2) A outorga de direito de uso dos recursos hídricos.

3) A cobrança pelo direito de uso da água.

4) O enquadramento dos corpos d'água em classes de uso.

5) O sistema nacional de informações sobre recursos hídricos.

Por fim, ressalte-se que a Lei 9.433/97 estabeleceu um arranjo institucional claro baseado em novos tipos de organizações para a gestão compartilhada do uso da água, tais como: (i) O Conselho Nacional de Recursos Hídricos; (ii) Os Comitês de bacias hidrográficas; (iii) As Agências da Água; (iv) As organizações civis de recursos hídricos.

Entretanto, neste quadro o grande desafio para a sociedade brasileira, incluindo seu meio técnico, é modificar a idéia atual, historicamente estabelecida, de que a expansão da oferta de água é a única solução para os problemas de recursos hídricos.

Neste contexto, as empresas de abastecimento de água são, regra geral, meras tocadoras de obras, principalmente. Falta-lhes a percepção do alcance que representa a inserção da água subterrânea como fator essencial de saúde pública e de grande alcance econômico, à medida que representa a alternativa mais barata $e$ amplia o fornecimento regular de água limpa de beber.

Por sua vez, a otimização dos usos da gota de água disponível, associada às diferentes funções dos aqüíferos na abordagem do gerenciamento integrado e, sobretudo, do reuso é, certamente, tão importante quanto a correspondente coleta, tratamento e disposição adequada dos esgotos domésticos, dos efluentes industriais e do lixo que se produz nas cidades, principalmente.

Portanto, a grande dificuldade de inserção da água subterrânea no Sistema Nacional de Gerenciamento de Recursos Hídricos resulta, em grande parte, do baixo custo da utilização racional da gota de água 
disponível. Além disso, é quase total o desconhecimento dos aspectos relacionados da água subterrânea como componente do ciclo hidrológico, tais como as suas condições de ocorrência, os sistemas de fluxos, as diferentes funções que poderiam ser desempenhadas pelos aqüíferos na abordagem do gerenciamento integrado, os volumes efetivamente extraídos pelos poços, as condições atuais de uso e conservação do manancial de água subterrânea.

\section{6. Água Subterrânea e "Crise da Água"}

O Brasil ostenta a maior descarga de água do mundo nos seus rios (260.000 $\mathrm{m}^{3} / \mathrm{s}$ ). Porém, este valor tem pouco significado prático, à medida que perto de $80 \%$ destas descargas estão nas regiões menos povoadas.

Entretanto, tendo em vista a grande função social da água, tem-se considerado como valor mais consistente, o quociente da descarga média de longo período dos rios de um país, região, estado ou bacia hidrográfica, pela respectiva população. Desta forma, as Nações Unidas classificam os países do mundo como muito pobre de água, isto é, dispõem de menos de 500 $\mathrm{m}^{3} / \mathrm{ano}$ per capita; pobre - entre 500 e 1000 $\mathrm{m}^{3}$ /ano per capita; regular - entre 1.000 e $2000 \mathrm{~m}^{3} / a n o$ per capita; suficiente - entre 2.000 e $10.000 \mathrm{~m}^{3}$ /ano per capita; rico entre 10.000 e $100.000 \mathrm{~m}^{3} /$ ano per capita e muito rico de água - mais de 100.000 $\mathrm{m}^{3}$ /ano per capita.

Neste quadro, a oferta de água de 48.176 $\mathrm{m}^{3}$ /ano per capita nos rios, coloca o Brasil na classe dos países ricos de água doce no mundo. Além disso, tem-se que a extração de apenas $25 \%$ da taxa de recarga dos nossos aqüíferos já representaria uma oferta de mais de $5.000 \mathrm{~m}^{3} / \mathrm{hab} / \mathrm{ano}$. Numa análise por unidade da federação no Brasil, chama a atenção o fato de na maioria dos nossos estados mais populosos ou desenvolvidos, as taxas serem superiores àquelas consideradas pelas Nações Unidas - 1.000 a $2.000 \mathrm{~m}^{3} /$ ano per capita - com suficientes ao usufruto de uma qualidade de vida moderna com desenvolvimento sustentável.

Entretanto, que significado tem esse quociente numa região onde os rios permanecem secos durante os períodos de estiagem, como é o caso de vastos domínios do semi-árido brasileiro? Por outro lado, em que pese o fato de perto de $80 \%$ das descargas dos nossos rios estarem nas áreas menos povoadas, a população dessas regiões apresenta índices de desenvolvimento humano - IDH - os mais baixos do Brasil. Além disso, tem-se que os Estados Unidos (p. ex.) com apenas $119.365 \mathrm{~m}^{3} / \mathrm{s}$ ou cerca de $9.000 \mathrm{~m}^{3}$ /ano per capita nos seus rios, ostenta a maior produção de grãos de todos os tempos numa vasta região de quase três milhões de quilômetros quadrados, cujo clima é árido com um coração desértico. Por sua vez, tem-se Israel com apenas $370 \mathrm{~m}^{3} / \mathrm{ano}$ per capita, porém, com índices de desenvolvimento humano - IDH muito superiores aos do Brasil de clima úmido. Mais grave, ainda, não se fala das águas subterrâneas, manancial acessível e a alternativa de abastecimento doméstico, principalmente, mais barata. Portanto, caracteriza-se que é mais importante saber usar a gota de água disponível do que ostentar sua abundância ou escassez.

\section{7. Água Subterrânea e Otimização dos Usos}

O desafio da conservação da natureza ar, água, energia, minerais, plantas e solo, principalmente - é tarefa para cada um de nós na vida diária. É igualmente tarefa de nossos vizinhos; dos governos nacionais, estaduais e municipais; de organizações mundiais, tais como a Organização das Nações Unidas (ONU).

Além disso, todas as formas de vida na Terra, inclusive o homem, precisam de água doce - aquela cujos teores de sólidos totais dissolvidos (STD) são inferiores a 1000 mg/L - para nascer, crescer e viver. Além disso, devido ao ciclo permanente de renovação das águas da Terra, existe tanta água doce no mundo de hoje como desde a origem dos tempos - e sempre existirá.

Porém, as demandas de água no mundo são cada vez maiores, devido ao crescimento da população humana, as mudanças dos processos de produção, hábitos de higiene, conforto e exigências de qualidade ambiental e de vida da população. Além disso, a degradação da qualidade das águas dos rios, principalmente, atinge níveis nunca imaginados, tanto nas cidades quanto no campo.

Assim, o uso cada vez mais eficiente da água disponível - chuva, rios, subterrânea, 
reuso, principalmente - é a única alternativa para se atender demandas crescentes com um recurso natural limitado. Vale ressaltar que esta possibilidade é uma experiência de sucesso comprovado em muitos países relativamente desenvolvidos do mundo.

Entretanto, apesar da menor quantidade de água doce da Terra $\left(0,3 \%\right.$ ou $104 \times 10^{3}$ $\mathrm{km}^{3}$ ) está nas calhas dos rios e nos lagos, esta tem constituído o manancial mais utilizado para abastecimento da população da Terra, cujos desperdícios e a degradação da sua qualidade atingem níveis nunca imaginados. Por outro lado, os progressos realizados durante as últimas décadas, principalmente, nos métodos de construção de poços, as crescentes performances alcançadas pelas bombas e a expansão da oferta de energia elétrica no mundo, em geral, e no Brasil, em particular, asseguram que os $29,9 \%$ ou $10,5 \times 10^{6} \mathrm{~km}^{3}$ de água subterrânea da Terra já não podem ser considerados inacessíveis.

Desta forma, até os aqüíferos profundos ou confinados são, atualmente, captados no Brasil para abastecimento público, industrial e agrícola, principalmente. Entretanto, esta utilização da água subterrânea continua sendo feita de forma empírica, improvisada e desordenada na maioria das Unidades da Federação.

Vale ressaltar que, além destas potencialidades naturais de água subterrânea no Brasil, tem-se a considerar aquelas que poderiam ser engendradas pelo gerenciamento integrado das diferentes funções dos aqüíferos, tais como: produção, filtro ou reuso, estocagem de enchentes dos rios e de excedentes sazonais ou temporários de água tratada, para regularização da oferta durante períodos de escassez ou de picos de demandas, transporte de águas de zonas distantes de recarga para setores de bombeamento intensivo, extração de águas geotermais, dentre outras.

Vale salientar que, durante as últimas décadas do século passado, a ênfase a abordagem integrada era o atendimento às exigências legais impostas pelas agências de fiscalização ambiental. Entretanto, os custos crescentes de abastecimento de água e de disposição dos efluentes levaram a uma avaliação mais abrangente dos sistemas hídricos e dos empreendimentos. Isso permite identificar oportunidades de otimização desses sistemas, sobretudo, pela introdução de práticas de recarga artificial de aqüíferos com água de enchentes dos rios, excedentes periódicos das estações de tratamento de água, recarga artificial de aqüíferos com esgoto tratado ou de reuso de efluentes para controle da interface marinha ou de plumas de poluição.

A partir dai, o objetivo maior do gerenciamento de recursos hídricos de uma bacia hidrográfica vem sendo à busca do uso mais eficiente possível da gota de água disponível, procurando a diminuição nos custos da produção industrial e agrícola, principalmente, de forma ambientalmente correta.

Portanto, não tem qualquer fundamento hidrológico o quadro de "crise de água" apresentado pelo Relatório das Nações Unidas sobre População de 2001, quando diz que no presente $54 \%$ das reservas disponíveis de água doce da Terra são utilizadas a cada ano e que esta cifra deverá atingir $70 \%$ em 2025 , só com o crescimento da população nos paises subdesenvolvidos.

Neste quadro, não se faz qualquer referência ao fato dos aqüíferos estocarem a maior reserva de água doce líquida da Terra. Por sua vez, a utilização da água subterrânea é, regra geral, a alternativa mais barata, pelo fato de ocorrendo de forma extensiva sob uma camada de solo não saturado, poder ser utilizada sem os elevados custos de adução e tratamento característicos da captação da água nos rios e lagos.

Além disso, omite-se o conceito de "substituição de fontes" preconizado pelo Conselho Econômico e Social das Nações Unidas, desde de 1986, segundo o qual, "a não ser que exista grande disponibilidade, nenhuma água de boa qualidade deve ser utilizada para usos que toleram águas de qualidade inferior". Portanto, esta situação torna claro que é mais importante saber usar a gota de água disponível do que ostentar sua abundância ou escassez.

\section{8. Água Subterrânea e o Regime dos Rios}

Bacia hidrográfica é o conjunto de terras banhadas por um rio e seus afluentes, diz o verbete de conceituados dicionários. Entretanto, este conceito não tem significado hidrológico, à medida que os rios e seus afluentes são, na realidade, os drenos naturais das águas que escoam pela superfície ou pelo subsolo da respectiva 
bacia hidrográfica. Regra geral, a descarga média de longo período dos rios constitui o limite superior da quantidade de água que pode ser captada numa bacia hidrográfica e os dados da Tabela 1 indicam que se tem rendimento hidrológico positivo em todas as principais bacias hidrográficas do Brasil.

Desta forma, a natureza renova continuamente a água da Terra por meio do ciclo hidrológico, sendo a água subterrânea a parcela das chuvas que infiltra nos terrenos da bacia hidrográfica e circula pelo seu subsolo. Entretanto, tendo em vista as pequenas velocidades dos fluxos subterrâneos - da ordem de $\mathrm{cm} / \mathrm{dia}$, contra velocidades de $\mathrm{km} / \mathrm{dia}$ do escoamento superficial - a sua contribuição alimenta o escoamento básico dos rios, isto é, aquele que ocorre durante o período de estiagem ou sem precipitação de água atmosférica chuva, neblina e neve, principalmente - na respectiva bacia hidrográfica.

Além disso, uma parcela da água que infiltra no solo dá suporte ao desenvolvimento da biomassa, constituindo o assim chamado Green Water Flow. Esta água é um recurso hídrico localizado, à medida que é consumida lá onde ocorre à precipitação de água atmosférica que Ihe deu origem.

Por sua vez, a descarga média total de longo período dos rios - escoamento superficial e subterrâneo - constitui o assim chamado Blue Water Flow. Trata-se de um recurso hídrico móvel, à medida que pode ser captado fora do local onde ocorreram às precipitações atmosféricas que lhe deu origem. O rendimento de uma bacia hidrográfica - relação porcentual da quantidade de chuva que é transformada em escoamento (Qt/P x100) - aponta a parcela da chuva que é transformada em recurso hídrico móvel ou Blue Water Flow.

O escoamento básico dos rios é uma boa medida das reservas reguladoras subterrâneas, ou seja, da taxa de infiltração nos terrenos onde foi esculpida a bacia hidrográfica em apreço. Desta forma, ao se medir o escoamento básico, ou seja, as descargas dos rios durante o período de estiagem ou sem chuvas numa bacia hidrográfica, tem-se uma indicação da importância da recarga da água subterrânea ou dos seus aqüíferos na área em apreço.

Tabela 1- Rendimento Hidrológico das Principais Bacias Hidrográficas do Brasil (REBOUÇAS, 1999)

\begin{tabular}{|c|c|c|c|c|c|c|}
\hline Bacia Hidrográfica & $\begin{array}{l}\text { Área } \\
\left(\mathrm{km}^{2}\right)\end{array}$ & $\begin{array}{l}\text { (P) média } \\
\text { (mm/ano) }\end{array}$ & $\begin{array}{c}\text { (Qt) } \\
\text { (mm/ano) }\end{array}$ & \begin{tabular}{|c|} 
Etp \\
médio \\
(mm/ano) \\
\end{tabular} & $\begin{array}{c}(\mathrm{Qt}) / \mathrm{P} \\
\%\end{array}$ & $\begin{array}{c}(Q t) \\
\%\end{array}$ \\
\hline $\begin{array}{l}\text { 1. Amazonas total } \\
\text { (Amazonas - Brasil) }\end{array}$ & $\begin{array}{c}6.112 .00 \\
3.844 .191^{*}\end{array}$ & $\begin{array}{l}2.542 \\
2.200\end{array}$ & $\begin{array}{l}1.041 \\
1.056\end{array}$ & $\begin{array}{l}1.502 \\
1.144\end{array}$ & $\begin{array}{l}41 \\
48\end{array}$ & 72,0 \\
\hline 2. Tocantins & 757.000 & 1.764 & 470 & 1.293 & 27 & 6,0 \\
\hline 3A. Atlântico Norte & 242.000 & 2.133 & 781 & 1.352 & 37 & 3,0 \\
\hline 3B. Atlântico Nordeste & 787.000 & 1.112 & 125 & 987 & 11 & 1,7 \\
\hline 4. São Francisco & 634.000 & 985 & 151 & 834 & 15 & 1,7 \\
\hline 5A. Atlântico Leste & 242.000 & 1.013 & 87 & 926 & 09 & 0,3 \\
\hline 5B. Atlântico Leste & 303.000 & 1.226 & 386 & 840 & 31 & 1,8 \\
\hline 6A. Paraná & $877.000^{*}$ & 1.434 & 402 & 1.032 & 28 & 6,5 \\
\hline 6B. Paraguai & $368.000^{*}$ & 1.397 & 115 & 1.283 & 08 & 1,0 \\
\hline 7. Uruguai & $178.000 *$ & 1.697 & 715 & 982 & 42 & 2,4 \\
\hline 8. Atlântico Sul & 224.000 & 1.479 & 643 & 836 & 43 & 2,5 \\
\hline $\begin{array}{l}\text { BRASIL + } \\
\text { Amazonas } \\
\text { internacional }\end{array}$ & 10.724 .000 & 2.044 & 737 & 1.307 & 36 & 140 \\
\hline
\end{tabular}

* extensão no Brasil, Dados básicos: Carta "Disponibilidade Hídrica do Brasil"- DNAEE, 1984 
Como corolário, um rio perene, ou seja, que nunca seca, indica que a recarga dos aqüíferos da bacia hidrográfica em questão é suficientemente importante para alimentar os seus fluxos durante os períodos sem chuvas. Este é o caso, por exemplo, dos rios que drenam os quatro milhões $\mathrm{km}^{2}$ de embasamento geológico de terrenos cristalinos/metamórficos do Brasil com espesso manto de alteração das rochas e os $3,5 \times 10^{6} \mathrm{~km}^{2}$ de terrenos sedimentares.

Ao contrário, quando um rio tem regime de fluxo temporário, ou seja, praticamente seca durante o período sem chuvas, indica que a recarga dos aqüíferos da referida bacia hidrográfica é limitada. Nesta situação enquadram-se as bacias hidrográficas esculpidas nos terrenos cristalinos, praticamente, impermeáveis e com possibilidades hidrogeológicas restritas às zonas de rochas fraturadas e aos retalhos do manto de alteração pouco espesso, tal como ocorre no Nordeste semi - árido.

Entretanto, as chuvas intensas que ocorrem na zona semi-árida do Nordeste geram recarga das zonas de rochas fraturadas aqüíferas do embasamento praticamente impermeável e dos retalhos de recobrimentos arenosos, de tal forma que se tem escoamento básico em todas as unidades de planejamento UP's do Nordeste, conforme mostram os dados da Tabela 2.

\section{Do Poço ao Sistema de Fluxos Subterrâneos}

Os estudos hidrogeológicos tradicionais compreendem, regra geral, uma descrição mais ou menos generalizada das condições de ocorrência da água subterrânea na área em apreço e uma análise estatística de poços - dados de níveis de água, produção e qualidade, principalmente - mesmo quando se ressalta a pouca consistência geológica e hidrogeológica destas informações.

Entretanto, a experiência internacional indica que se deve evoluir da análise do poço ou de outro dado pontual, à compreensão dos sistemas de fluxos subterrâneos que se desenvolvem na área em apreço.

Neste particular, a camada ou corpo rochoso onde a água subterrânea ocorre e circula configura um sistema de fluxos subterrâneos, à medida que tem uma zona de recarga que se interrelaciona com outra de descarga por meio de processos hidrogeológicos e geoquímicos aleatórios ou determinísticos (TÖTH, 1995).

Por sua vez, o sistema de fluxo da água no subsolo da bacia hidrográfica em apreço poderá abranger dimensões locais, intermediárias ou regionais, nas quais os tempos de trânsito da água subterrânea poderão compreender, respectivamente, dias, anos, séculos ou milênios (Figura 1).

Além disso, como a quantidade de fluxo que entra numa célula unitária do aqüífero livre ou não confinado e confinado - é igual à quantidade que sai, as descargas de base dos rios são medidas consistentes das taxas de recarga dos aqüíferos da bacia hidrográfica em questão.

Entretanto, como a água que infiltra no meio poroso ou fissural tem, regra geral, velocidades muito baixas de circulação, significa que 0 seu monitoramento quantidade ou qualidade - realizado em tempo real, tal como ocorre no caso dos rios, significa incrementos substanciais de custos.

Desta forma, torna-se necessário implantar uma criteriosa rede de amostragem, pois não é possível misturar dados de poços rasos, cujas águas provêem, regra geral, de um sistema de fluxo local, com dados de poços profundos que captam sistemas de fluxos intermediários ou regionais.

Por sua vez, a consideração dos sistemas de fluxos subterrâneos torna obsoleto o conceito de safe yield dos aqüíferos de uma área, segundo o qual o volume máximo explotável era representado pela sua taxa de recarga natural (MEINZER, 1923). 
Tabela 2 - Balanço Hídrico nas Unidades de Planejamento - UP's do Nordeste (REBOUÇAS, 1999).

\begin{tabular}{|c|c|c|c|c|c|}
\hline $\begin{array}{c}\text { Unidades } \\
\text { Planejamento UP's } \\
\end{array}$ & $\begin{array}{r}\text { Área } \\
\left(\mathrm{km}^{2}\right) \\
\end{array}$ & $\begin{array}{c}\mathbf{P} \\
\text { (mm/ano) } \\
\end{array}$ & $\begin{array}{c}\text { (Qs) } \\
\text { (mm/ano) } \\
\end{array}$ & $\begin{array}{c}\text { (Qb) } \\
\text { (mm/ano) } \\
\end{array}$ & $\begin{array}{c}\text { Qb/Qs } \\
(\%)\end{array}$ \\
\hline 1. Tocantins & 32.900 & 1500 & 166 & 15 & 9 \\
\hline 2. Gurupi & 50.600 & 1840 & 302 & 49 & 16 \\
\hline $\begin{array}{l}\text { 3. Mearim-Grajau - } \\
\text { Pindaré }\end{array}$ & 97.000 & 1550 & 146 & 35 & 24 \\
\hline 4. Itapecuru & 54.000 & 1450 & 143 & 29 & 20 \\
\hline $\begin{array}{l}\text { 5. Munim- } \\
\text { Barreirinhas }\end{array}$ & 27.700 & 1750 & 205 & 113 & 55 \\
\hline 6. Parnaíba & 330.000 & 1030 & 94 & 27 & 29 \\
\hline 7. Acaraú-Coreaú & 30.500 & 970 & 128 & 44 & 34 \\
\hline 8. Curu & 11.500 & 880 & 175 & 30 & 17 \\
\hline 9. Fortaleza & 14.700 & 990 & 118 & 36 & 30 \\
\hline 10. Jaguaribe & 72.000 & 790 & 46 & 11 & 24 \\
\hline 11. Apodi-Mossoró & 15.900 & 710 & 33 & 19 & 57 \\
\hline 12. Piranhas- Açu & 44.100 & 640 & 48 & 13 & 27 \\
\hline 13. Leste Potiguar & 24.440 & 690 & 39 & 30 & 77 \\
\hline 14. Leste Paraíba & 23.760 & 690 & 54 & 38 & 70 \\
\hline $\begin{array}{l}\text { 15. Leste } \\
\text { Pernambuco }\end{array}$ & 25.300 & 1040 & 133 & 37 & 28 \\
\hline 16. Bacias Alagoas & 17.100 & 1280 & 84 & 96 & 114 \\
\hline 17. São Francisco* & 487.000 & 910 & 50 & 34 & $68^{\star \star}$ \\
\hline 18. Vaza Barris & 22.330 & 760 & 36 & 17 & 47 \\
\hline 19. Itapicuru-Real & 46.100 & 770 & 26 & 19 & 73 \\
\hline $\begin{array}{l}\text { 20. Paraguaçu- } \\
\text { Salvador }\end{array}$ & 81.560 & 930 & 52 & 51 & 98 \\
\hline 21. Contas- Jequié & 62.240 & 870 & 78 & 11 & 14 \\
\hline 22. Pardo-Cachoeira & 42.000 & 1260 & 141 & 29 & 20 \\
\hline 23. Jequitinhonha* & 23.200 & 1030 & 240 & 23 & 9 \\
\hline 24. Extremo S. Bahia & 27.300 & 1320 & 56 & 199 & 355 \\
\hline $\begin{array}{c}\text { NORDESTE- } \\
\text { SUDENE } \\
\text { Volumes Qs e Qb- } \\
\mathrm{Hm}^{3} \text { lano }\end{array}$ & 1.663 .200 & 1140 & $\begin{array}{c}89 \\
(149.000)\end{array}$ & $\begin{array}{c}35 \\
(58.000)\end{array}$ & $\begin{array}{l}39 \\
39\end{array}$ \\
\hline
\end{tabular}

- Área da UP dentro do Nordeste (SUDENE, 1980, ÁRIDAS, 1995),

- ** Incluindo contribuição do Alto S. Francisco fora área SUDENE

A análise dos sistemas de fluxos subterrâneos nas principais bacias hidrogeológicas do Centro Oeste dos Estados Unidos, configura um sensível incremento dos seus potenciais nas fases de pré-desenvolvimento e desenvolvimento (Figura 2). 


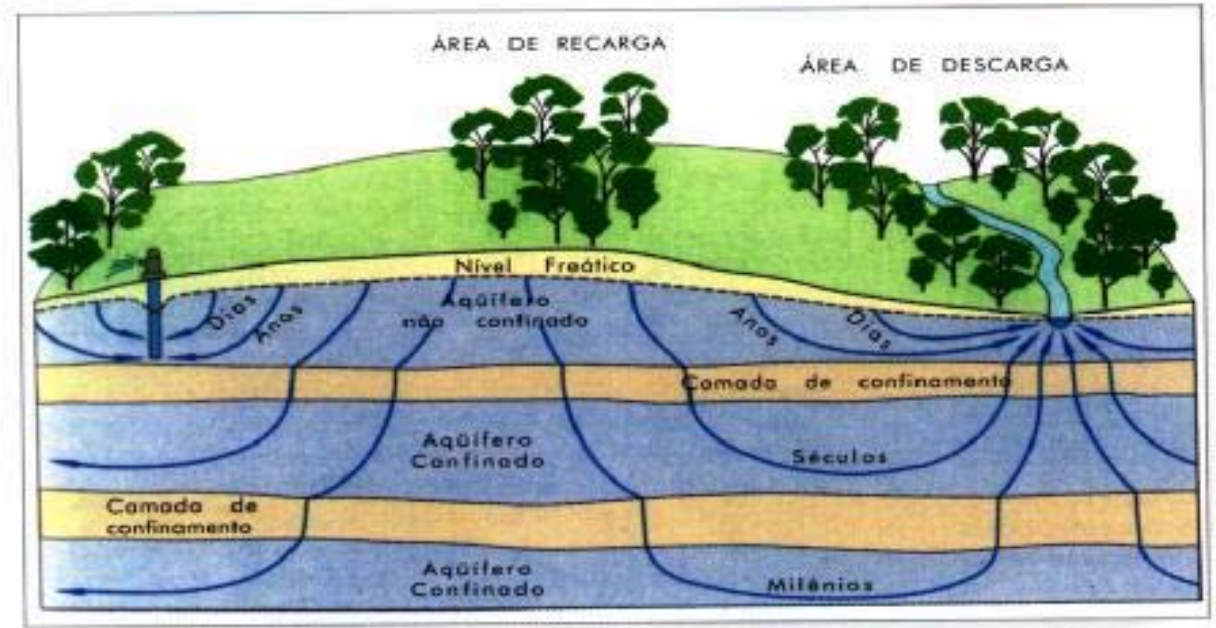

Figura 1- Do poço ao sistema de fluxos subterrâneos

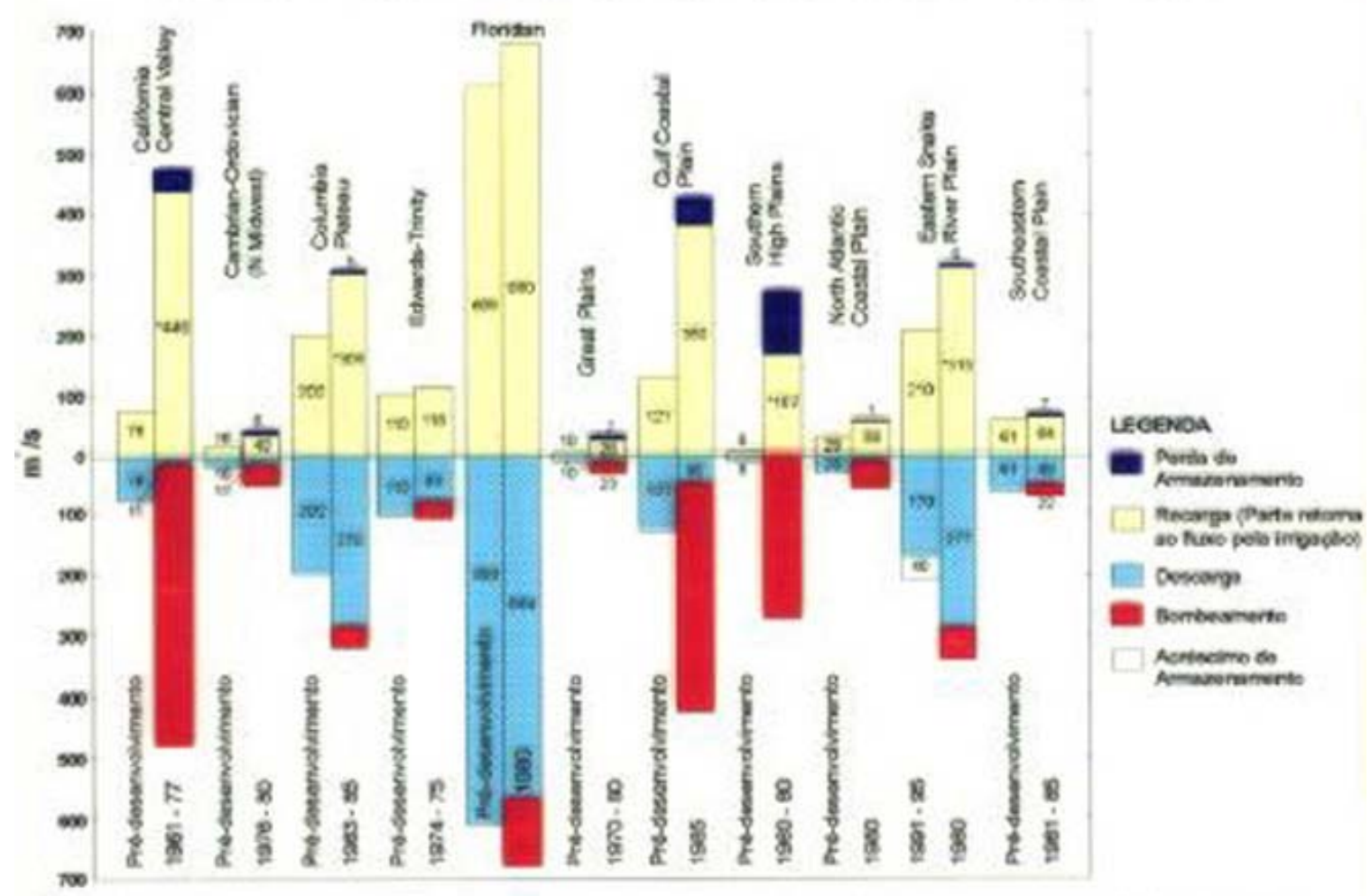

Figura 2- Mudanças das taxas de recarga dos aqüíferos nas principais bacias hidrogeológicas do Centro Oeste dos Estados Unidos (JOHNSTON, 1997).

Por sua vez, no início da fase sistêmica, a ênfase era o atendimento às exigências legais impostas pelas agências de fiscalização ambiental. Entretanto, os custos crescentes do abastecimento de água e de disposição de efluentes, levaram a uma avaliação mais abrangente dos sistemas hídricos e dos empreendimentos. Isso permitiu identificar oportunidades de otimização desses sistemas, principalmente pela introdução de práticas de uso cada vez mais eficiente e até de reciclagem ou de reuso de efluentes. 
A partir daí, o objetivo maior da análise sistêmica vem sendo a busca de eficiência do uso da água disponível de chuva, de rios, subterrânea de reuso, principalmenteprocurando a obtenção de maiores ganhos econômicos, aos quais juntam-se dois outros: um, de natureza operacional: outro, vinculado a imagem do empreendimento. $O$ primeiro, de natureza operacional, à medida que com o tratamento de efluentes para reuso, o empreendimento acaba dispondo de uma fonte alternativa de abastecimento, de extrema importância em regiões onde o fornecimento de água não é seguro ou onde a fonte própria da empresa está operando próximo ao limite. O segundo está ligado à imagem do empreendimento, já que a prática do uso eficiente ou do reuso da água acaba revelando a preocupação de reduzir a poluição representada pelo menor volume de descargas poluidoras.

Dependendo do volume de água por unidade de produção, a economia pode representar um fator de considerável importância à viabilização do empreendimento em questão. Na verdade, não são raros os casos em que a introdução do uso eficiente da gota d'água disponível ou de reuso reduz para menos da metade os custos da água na indústria, sobretudo, segundo os conceitos do usuário - pagador e do poluidor- pagador previstos na Lei Federal 9.433/97, os quais determinam que os responsáveis pelo uso e degradação do ambiente, em geral, e da água, em particular, devem ser imputados os custos relacionados às ações necessárias para que o ambiente e a água permaneçam em estado aceitável. Assim, a cobrança deverá ser aplicada como um instrumento indutor do uso racional da gota de água disponível, incentivando o seu uso cada vez mais eficiente.

\section{Conclusões}

À medida que a água subterrânea ocorre sob uma espessura mais ou menos importante de material não saturado filtrante, está relativamente protegida dos agentes de poluição que atingem rapidamente os rios e outros corpos de água superficiais. Como corolário, a água subterrânea pode ser, regra geral, consumida sem os custos dos métodos de clarificação, tratamento e adução que se tornam indispensáveis, quando a água de beber é captada num rio, açude ou lagoa.

Esta situação está engendrando um incremento inusitado na utilização da água subterrânea pelo setor privado, principalmente, ao mesmo tempo em que o necessário controle dos setores públicos Federal, Estaduais ou Municipais, torna-se cada dia mais frouxo ou confuso.

Desta forma, a inserção da água subterrânea no Sistema Nacional de Gerenciamento dos Recursos Hídricos representa um grande desafio à sociedade brasileira, incluindo seu meio técnico, cuja idéia, historicamente estabelecida, é a realização de grandes investimentos como única solução para os problemas de recursos hídricos. Por outro lado, pouco se fala em gestão das demandas, embora sejam cada vez mais freqüentes as experiências de sucesso comprovado em muitos países desenvolvidos, da possibilidade de se atender demandas hídricas futuras por meio da maior eficiência dos usos atuais e utilização das águas subterrâneas.

Portanto, a inserção da água subterrânea no Sistema Nacional de Gerenciamento de Recursos Hídricos implica no enfrentamento de três desafios principais:

1) A falta de conhecimento do público em geral, do meio técnico e dos tomadores de decisão sobre as condições de uso e proteção das águas subterrâneas. Desta forma, justificam-se as formas empíricas e improvisadas de sua utilização, omitindo-se com freqüência, que o seu uso racional e as múltiplas funções que poderão ser desempenhadas pelos aqüíferos são as alternativas mais baratas para desenvolvimento do moderno agronegócio, bem como para abastecimento do consumo humano e industrial, principalmente.

2) A transformação dos "bandos" de dados disponíveis em diversos órgãos- Federais e Estaduais, principalmente- em um banco de dados verdadeiramente acessível ao público em geral e finalmente, em Sistemas de Informações do tipo SIG ou similar, para uso dos setores responsáveis pelo Sistema Nacional e Estaduais de Gerenciamento dos Recursos Hídricos.

3) Realização de investimentos, sobretudo, para formação de recursos humanos nas 
tarefas de planejamento, uma vez que os estudos e os poços sendo feitos ao custo e risco do setor privado, principalmente, não houve investimento público realização dos estudos e para

\section{Referências Bibliográficas}

Associação Brasileira da Industria de Águas Minerais- ABINAM/Departamento Nacional da Produção Mineral- DNPM, 1995, Água Mineral do Brasil-Retrato Histórico da Industria Engarrafadora. p. 109. Rio de Janeiro.

BARTH, F. T. (1999). Aspectos Institucionais do Gerenciamento de Recursos Hídricos, p. 565-599, In Rebouças, A.C., Braga, B., Tundisi, J. G., 1999, Águas Doces no Brasil, Capital Ecológico, Uso e Conservação, p. 717. IEA/USP, ABC. São Paulo.

CETESB- Cia Estadual de Tecnologia de Saneamento Básico e Ambiental, 1998, Relatório de qualidade das águas subterrâneas do Estado de São Paulo. 95 p. São Paulo.

COSTA, W. D. (2001). Legislação de Águas Subterrâneas e Gerenciamento de Aqüíferos, Anais XII Encontro Nacional de Perfuradores de Poços, IV Simpósio de Hidrogeologia do Nordeste. p. 77-82, Recife.

EDIPRO- Edições Profissionais Ltda. Código de Águas e legislação complementar revista e atualizada. $2^{a}$ Edição, 1996. Rio de Janeiro.

Instituto Brasileiro de Geografia e Estatística- IBGE, 1992, Pesquisa Nacional de Saneamento Básico, Tab. 3, p. 4. Rio de Janeiro.

Instituto Brasileiro de Geografia e Estatística- IBGE, 2000, Censo Demográfico. Rio de Janeiro.

JOHNSTON, R. H., 1997, Sources of water supplying pumpage from regional aquifer systems of the United States, Hydrogeology Journal, v. 5, $n^{\circ} 2$, pp 54-63.

MEINZER, O. E., 1923, Outline of groundwater in hydrology with definitions.U. S. Geol. Surv. Water Supply Paper, 494. monitoramento e controle - Federal, Estaduais ou Municipais- necessários ao desenvolvimento de uma sadia mentalidade hidrogeológica no Brasil.

Ministério do Meio Ambiente- MMA, Secretaria Nacional de Recursos Hídricos$\mathrm{SRH}, 2001$, Política Nacional de Recursos Hídricos- Legislação, 54 p. Brasília.

PACHECO, A., REBOUÇAS, A. C. 1982, Aspectos de uso e preservação das águas subterrâneas da Grande São Paulo. In $2^{\circ}$ Cong. Bras. Águas Subterrâneas, Salvador, p. 389-401. Salvador.

REBOUÇAS, A. C. (1999). Águas Subterrâneas, p. 117-151. In Águas Doces no Brasil- Capital Ecológico, Uso e Conservação, pp 717. IEA/USP-ABC. São Paulo.

REBOUÇAS, A. C., RICCOMINI, C., ELLERT, N., DUARTE, U., MELLITO, K. M., SENF, L. A., SOUZA, J. C. S. (1994) Diagnóstico Hidrogeológico da Região Metropolitana de São Paulo- RMSP. Anais Cong. Brás, Águas Subterrâneas, p. 93-102, Recife.

TELLES, D. D'A. (1999). Água na Agricultura e Pecuária, p. 305- 337. In REBOUÇAS. A. C., BRAGA, B., TUNDISI, J. G. (1999) Águas Doces no Brasil- Capital Ecológico, Uso e Conservação, 717 p. IEA/USP-ABC. São Paulo.

TOMANIK, C. P. (1999) Águas Doces no Direito Brasileiro, p. 601-635, In REBOUÇAS, A. C., Braga, B., Tundisi, J. G., 1999, Águas Doces no Brasil, Capital Ecológico, Uso e Conservação, p. 717.IEA/USP, ABC. São Paulo.

TÖTH, J. 1995, Hydraulic continuity in large sedimentary basins, Hydrogeology Journal, v. $3, n^{\circ} 4, p p$ 4-6. 